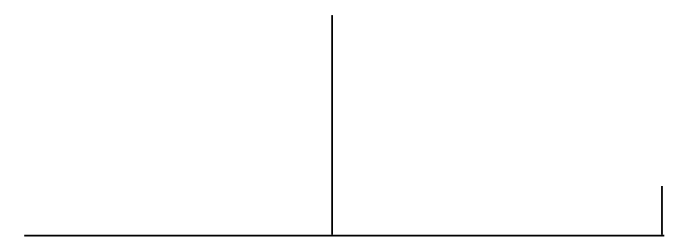

Rev. Latinoam. Psicopat. Fund., São Paulo, v. 13, n. 3, p. 517-521, setembro 2010

Interlocuções sobre o feminino na clínica, na teoria, na cultura Silvia L. Alonso, Daniele M. Breyton e Helena M.F.M. Albuquerque São Paulo: Escuta/Instituto Sedes Sapientiae, 2008, 416p

\title{
"Ele não tem xoxota!": a lógica do falo ou a lógica da diferença?
}

Noemi Moritz Kon

O campo conceitual do feminino tem se mostrado como a grande oportunidade de renovação, ou mesmo de revolução, para a reflexão psicanalítica. Ele é vetor para a denúncia da manutenção da fraude do paradigma falocêntrico, marca totêmica aparentemente incontornável do pensamento freudiano, figura basilar ainda hoje na mainstream do universo psicanalítico.

Desnecessário realçar uma vez mais a insuficiência da especulação freudiana no que se refere à compreensão da sexualidade feminina - na qual a castração e a inveja do pênis conformariam o exíguo universo do que pode e quer uma mulher -, ainda que essa falha possa ser de alguma forma justificada ao se levar em conta o contexto no qual Freud construiu sua poderosa obra, ou seja, já no final do que se convencionou chamar de modernidade ocidental, e 


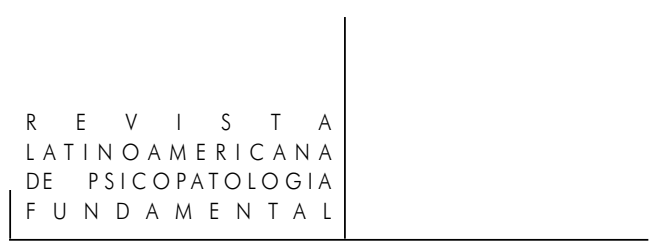

que se apoiou, justamente, nas ideias de ordem, razão e natureza para garantir sua pensabilidade.

Freud rompeu com alguns tantos a prioris que fundamentavam a inteligibilidade de seu momento histórico: assumiu a linguagem e a sexualidade como elementos instituintes do humano e estabeleceu um território inédito e de outra racionalidade, o inconsciente, criando desta maneira um novo homem, o homem psicanalítico.

Freud pôde muito, mas não tudo!, afirmação que justamente nos encaminha para a matéria pulsante que subjaz e resiste sob as tacanhas ideias freudianas sobre o feminino e para a possível contribuição que esta ordem conceitual pode ter na complexificação, na ampliação e mesmo na subversão da metapsicologia e do fazer psicanalíticos. Sob as bases do engodo da lógica do fálico/castrado insinuam-se a incompletude e a alteridade, figuras do negativo que apontam para o ensejo de uma nova ética nas relações com o outro, ou seja, entre mulheres e homens, mulheres e mulheres e homens e homens. Pois o feminino diz respeito ao humano, a todos nós quando não nos furtamos a lidar com a falta e o desamparo, ou seja, com a dor do desmascaramento do logro do discurso fálico do absoluto e da perfeição.

Escrevo esse preâmbulo e toda a continuidade dessa resenha como resultado da significativa reflexão que estabeleci no diálogo com a instigante produção dos autores de Interlocuções sobre o feminino na clínica, na teoria, na cultura, coletânea organizada por Silvia Alonso, Danielle Breyton e Helena Albuquerque, resultado da II Jornada Temática do Departamento de Psicanálise do Instituto Sedes Sapientiae, realizada em maio de 2007, e que é fruto da extensa elaboração que o Grupo de trabalho e pesquisa "O feminino e o imaginário cultural contemporâneo", capitaneado por Silvia Alonso, vem desenvolvendo desde o ano de 1997. O convite para uma reflexão conjunta sobre o feminino, naquilo que ele apresenta de mais subversivo, evidencia uma faceta vital que movimenta esta associação de psicanalistas em sua busca de uma psicanálise não conservadora ainda que bem embasada no legado freudiano. A máxima de Goethe adotada por Freud - de receber a herança que nos cabe e fazê-la nossa - tem aqui seu lugar.

Alguns veios apresentados nos 32 artigos que compõem o livro permitem discernir certos denominadores comuns, certos patamares de reflexão, ou seja, certa tonalidade harmônica que congrega os autores: pensar a psicanálise na história, refletir sobre as transformações pelas quais passou o lugar social da mulher - e também o do homem - nos séculos XIX, XX e XXI, manter o diálogo reciprocamente fertilizador com as produções culturais e artísticas, estabelecer uma visada crítica à dogmática psicanalítica e trabalhar a partir da distinção entre sexo biológico e gênero (entendido como conjunto de predicados e papéis que 
uma determinada cultura confere aos indivíduos em função do sexo ao qual pertencem), o que permitiria romper com a sedução de um pensamento naturalizante e denunciar a violência da ideologia e da dominação que regem o discurso instituído sobre a sexualidade feminina.

Um posicionamento decisivo, e que perpassa grande parte dos textos, é o de que o poder insidioso do discurso falocêntrico, em suas inúmeras formas e modalidades, deve ser denunciado, nomeado, criticado e desconstruído para que uma nova perspectiva psicanalítica possa fazer presença, uma perspectiva própria ao campo do feminino, que não se ancora no dualismo fálico/castrado, winner/loser.

Não que para tanto não se deva desconfiar de um consenso fácil, e nada ingênuo, que poderia alçar o feminino - numa pura repetição do repúdio à castração - a uma reconfiguração do falo. O feminino não é um elixir para todas as faltas: pode funcionar, sim, se tivermos sorte e empenho, como oportunidade de criação, como convite para o encontro com a diferença e a alteridade, como ocasião propícia de questionamento da ordem falocêntrica que exige submissão.

Mas sabemos que o paradigma fálico permanece como moeda corrente e precisa ser apontado e combatido cotidianamente em sua potência destrutiva que domina mulheres e homens por meio de um discurso que nos faz acreditar que ter é ser. Pois, em função de sua força, construímos loucuras às quais nos sujeitamos para não sermos marginais no mundo do consumo de consolo, para imaginarmo-nos parte do que passou a ser valor: tornamo-nos adictos às drogas, às medicações, aos alimentos, ao sexo, às cirurgias, ao trabalho, à rapidez, ao poder, à celebrização, ao dinheiro, tornamo-nos doentes de pânico e do controle, mas também de euforia e de depressão, tornamo-nos armazenadores, colecionadores de objetos, de conhecimentos, de afazeres, de tecnologias, de silicones, de pessoas. Não conseguimos mais manter um ritmo adequado para o trabalho da reflexão, pois é insuportável a denúncia de que jamais atingiremos a paralisia do acabamento, e isto justamente porque precisamos do oco e do desejo para que a vida possa acontecer.

E o golpe do discurso falocêntrico recai prioritariamente sobre as mulheres. São elas aquelas especialmente subjugadas pela violência - por vezes silenciosa, mas não menos mortífera -, pela ideologia do falo que impera em nossa sociedade. Se mesmo Freud, o grande libertador da fala da mulher no final do século XIX, não foi capaz de encontrar um destino que não o patológico - inibição neurótica, masculinização e investimento libidinal no pai, na tentativa de reverter a castração supostamente consumada por meio da aquisição de um filho/pênis/falo/ prótese - para as mulheres e sua sexualidade criadora, a maternidade, o que será de outros discursos disciplinadores que procuram ordenar nossa percepção e nos- 


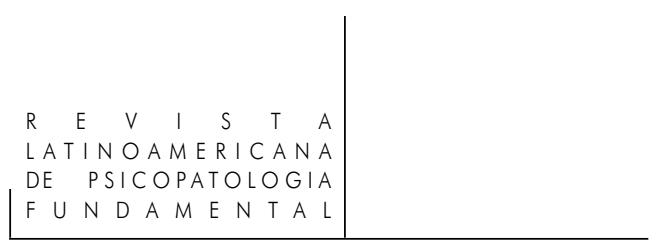

sa concepção do mundo? No desaparecimento de Deus, do Rei e do Pai, as sociedades contemporâneas montam-se ao redor da figura do bem-dotado, do bem-sucedido, daquele que, munido do saber/poder, trabalha em prol da manutenção do status quo, no qual a disparidade do privilégio (a menor para o outro, é claro) é oportunidade de gozo. À mulher é reservado um papel exemplar daquele que não tem. Num discurso de consenso, à mulher falta o pênis. Impossível imaginar que o homem seria nomeado aquele a quem falta uma xoxota! ${ }^{1}$ Pois ao homem (o detentor do poder por sua própria natureza), é óbvio, nada falta! Não pode faltar! Alguém precisa ser completo!

É este o núcleo duro do discurso falocêntrico, núcleo que se dilata, enrijece, penetra e ordena as organizações familiares, laborais, estéticas, políticas, religiosas, acadêmicas, jurídicas, médicas etc, criando, para a manutenção de si próprio (do discurso totalizante), cidadãos de diferentes classes; é este mesmo discurso que estrutura as relações sociais e que se dissemina na mensagem da mídia e dos especialistas que nos arrasta na informação e que coisifica o corpo e a alma da mulher (como representante daquele a quem falta), especifica e prescreve o que e como ela deve ser.

O trabalho do feminino tem a imensa responsabilidade de denunciar este estado de coisas, de se insurgir contra a caducidade de certas perspectivas ainda tão pregnantes relativas à mulher - bem como a outros grupos colocados à margem do epicentro do poder fálico - e que procuram transformar a mínima diferença em descalabro de desigualdades. Pois sabemos, todos, que nós, psicanalistas, tampouco estamos imunes ao poderio da sedução tecnicista do cientificismo e da ideologia, com seu discurso fora do tempo e fora do lugar, e somos aptos a nos apropriar, e com plena satisfação, do status integral do especialista que, na prerrogativa de seu suposto saber, tudo conhece e tudo controla. As consequências sociais da adoção do discurso alienante da verdade já dada - todos as conhecemos - são atrozes; as consequências clínicas do não enfrentamento da linguagem do falo e da reiteração da castração, sob o disfarce do conhecimento universal, legitimado e neutro do discurso competente, ${ }^{2}$ são implacáveis: enlou-

1. Refiro-me à frase "Porque ele não tem xoxota!" - expressão de obviedade pela qual uma menina de menos de dois anos caracterizava como do sexo masculino o bebê nu que via numa fotografia , reproduzida por Flavio Carvalho Ferraz em "O primado masculino em xeque", in Alonso, S.L.; Breyton, D. M. e Albuquerque, H.M.F.M. (Orgs.). Interlocuções sobre o feminino na clínica, na teoria, na cultura. São Paulo: Escuta/Instituto Sedes Sapientiae, 2008. p. 67-68.

2. Penso aqui no antigo e ainda tão atual trabalho de Marilena Chaui, "O discurso competente". In: Cultura e democracia, o discurso competente e outras falas. São Paulo: Moderna, 1981. 
quecimento, debilidade, reificação, passividade, perversão, sofrimento inominável, submissão, frustração, inveja, ressentimento, fracasso...

Imensa responsabilidade!

O contraponto crítico que o trabalho do feminino pode permitir é nossa oportunidade de encontro com a alteridade, é o convite para criação em parceria de uma outra ética do humano.

Interlocuções sobre o feminino na clínica, na teoria, na cultura assume ativa e corajosamente tal responsabilidade e trabalha nesta mesma direção de esperança: oferece-se como abertura, como convite, como oportunidade para se pensar, em mutualidade, as potências do desamparo e da falta - aquilo que foi chamado por Silvia Bleichmar de "castração ontológica"3 do humano -, e como ocasião de discernimento da experiência de inacabamento que é o viver.

3. Bleichmar, S. Seminário sobre "Ética", São Paulo, 2006, expressão citada por Vera B. Zimmermann em "E as meninas estão chegando... e brigando...". In: Alonso, S. L.; Breyton, D. M. e Albuquerque, H.M.F.M. (Orgs.). Interlocuções sobre o feminino na clínica, na teoria, na cultura. São Paulo: Escuta/Instituto Sedes Sapientiae, 2008. p. 364.

\section{NoEMI Moritz Kon}

Psicanalista, Membro do Departamento de Psicanálise do Instituto Sedes Sapientiae (São Paulo, SP, Brasil); Mestre e Doutora pelo Departamento de Psicologia Social do Instituto de Psicologia da Universidade de São Paulo - USP (São Paulo, SP, Brasil); Autora de Freud e seu duplo. Reflexões entre psicanálise e arte (São Paulo, Edusp/Fapesp, 1996); A viagem: da literatura à psicanálise (São Paulo, Companhia das Letras, 2006); Organizadora de 125 contos de Guy de Maupassant (São Paulo, Companhia das Letras, 2009); Professora dos cursos de pós-graduação: "Conflito e Sintoma: Clínica Psicanalítica" do Departamento de Psicanálise do Instituto Sedes Sapientiae e "Psicopatologia e Saúde Pública" da Faculdade de Saúde Pública da USP.

R. Augusta 2445, cj. 2

01413-100 São Paulo, SP, Brasil

Fone: (11) 3083-6193

e-mail: kononi@aclnet.com.br 